\title{
Aluminum Hydroxide/Magnesium Hydroxide
}

National Cancer Institute

\section{Source}

National Cancer Institute. Aluminum Hydroxide/Magnesium Hydroxide. NCI Thesaurus. Code C1149.

An oral suspension containing aluminum hydroxide and magnesium hydroxide, with antacid effects. Aluminum hydroxide and magnesium hydroxide neutralizes or reduces gastric acid, thereby relieving symptoms associated with indigestion, gastritis, and gastroesophageal disease (GERD). Combined with other liquid ing redients (such as lidocaine and diphenhydramine), this antacid provides relief for painful stomatitis, mucositis, and esophag itis associated with both chemotherapy and radiation therapy. 